\title{
Convergencias y divergencias lingüísticas con el judeoespañol castizo de un traductor nativo de inglés. El caso del Ele Toledot Bené Yisrael (Constantinopla, 1854 y 1886) del Rev. Alexander Thomson*
}

\author{
Daniel Martín González** \\ Universidad Complutense de Madrid \\ ORCID ID: https://orcid.org/0000-0002-7587-2108
}

A pesar de la existencia de una opinión negativa generalizada sobre el judeoespañol empleado por los misioneros protestantes, no existen actualmente estudios que expliquen de manera exhaustiva las diferentes características lingüísticas del idioma producido por estos cristianos, así como tampoco que hagan una investigación que analice la evolución de estas en el tiempo. En las próximas páginas mostraremos el caso particular del reverendo escocés Alexander Thomson (1820-1899), quien tradujo del inglés al judeoespañol diferentes obras en la década de 1850 en Constantinopla y posteriormente las retradujo entre mediados y finales de la década de 1880 . De este modo, podremos atestiguar cómo evoluciona el uso de la lengua sefardí en un hablante no nativo a través de sus textos traducidos a lo largo de tres décadas.

PALABRAS ClaVE: Adquisición de lengua extranjera; literatura pedagógica; misioneros protestantes; Imperio otomano; siglo XIX.

Linguistic Convergence and Divergence with Regular Judeo-Spanish in the 19th Century by a Native English Translator: The Case of Ele Toledot Bené YISRAEL (CONSTANTINOPLE 1854 AND 1886).- Despite the existence of a widespread negative impression of the Judeo-Spanish employed by Protestant missionaries, there is neither a detailed study shedding light on the different linguistic traits of the language produced by these Christians nor a research analyzing the evolution of these throughout

* El presente artículo se ha elaborado en el marco del proyecto posdoctoral titulado «The influence of ideology in the process of foreign language acquisition / La influencia de la ideología en el proceso de adquisición de una lengua extranjera» financiado por la Universidad Complutense de Madrid (CT27/16-CT28/16) así como en el marco del Proyectos de Investigación del Plan Nacional «Sefarad, siglo XXI (2017-2020): Edición y estudio filológico de textos sefardíes» financiado por el MINECO (ref. núm. FFI201674864-P)

**danielma@ucm.es

Copyright: (C) 2020 CSIC. Este es un artículo de acceso abierto distribuido bajo los términos de la licencia de uso y distribución Creative Commons Reconocimiento $4.0 \mathrm{In}$ ternacional (CC BY 4.0). 
time. In the following pages we will show the special case of the Scottish reverend Alexander Thomson (1820-1899), who translated several works from English into JudeoSpanish in the 1850s in Constantinople and later retranslated them between the mid1880 s and the end of that decade. Thus, we will be able to reveal how this language evolved in a non-native Judeo-Spanish speaker through his translated texts throughout three decades.

KeYwords: Foreign language acquisition; Pedagogical literature; Protestant missionaries; Ottoman Empire; 19th Century.

\section{INTRODUCCIÓN}

Dentro del panorama histórico de la literatura sefardí, tan innegable es la importancia de las obras, bien escritas o bien traducidas, por los misioneros protestantes con fines proselitistas en el Imperio otomano, que Elena Romero ya las recoge en su famoso repaso de la historia de la creación literaria en lengua sefardí ${ }^{1}$. Como ella misma señaló hace tres décadas, la lengua de estos misioneros era «un judeoespañol muy españolizado y lejano» ${ }^{2}$ de lo que se entendía como castizo en aquel momento. Desde entonces, existe un amplio consenso entre los académicos con respecto a la lengua en que los misioneros protestantes se expresaban en sus textos escritos -aunque no sabemos cómo hablaban, pues no hay registros orales-, y se considera un uso del idioma poco prototípico para el judeoespañol del siglo XIX ${ }^{3}$.

1 Vid. Elena Romero, La creación literaria en lengua sefardí (Madrid: Mapfre, 1992) págs. 59-60, 134 y 201.

2 En Romero, Creación, pág. 59.

${ }^{3}$ Numerosos autores se han pronunciado al respecto. En orden cronológico, el primero de todos es David M. Bunis («The language of the Sephardim: A historical overview», en Moreshet Sepharad: The Sephardi legacy [Jerusalem: The Magnes PressThe Hebrew University, 1992] págs. 399-442: 411) quien catalogó el idioma de los misioneros como un «pseudo-Sephardi vernacular (essentially a blend of Old and Modern Spanish transcribed in the Hebrew alphabet)». Moshe Lazar (en «Apéndice: Ladinamientos aljamiados de la Biblia», en Actas del Simposio Internacional sobre la Biblia de Ferrara, eds. Iacob M. Hassán y Ángel Berenguer [Madrid: Consejo Superior de Investigaciones Científicas, 1994] págs. 373-442: 407-408) fue el primero en afirmar que los escritos de los misioneros en judeoespañol fueron más bien un intento de sefardización de la lengua. Aldina Quintana RodRíGuez («Proceso de recastellanización del judesmo», en Jewish Studies at the Turn of the Tweentieth Century, eds. Judith 
Este estudio se concibe con el fin de entender por qué podemos (o no) categorizar como verdadero judeoespañol la lengua de uno de sus autores más prolíficos en el siglo XIx. Para ello analizaremos una obra traducida del inglés en 1854 y posteriormente retraducida en 1886: el libro Ele Toledot Bené Yisrael, del Rev. Alexander Thomson.

\section{La misión protestante para los Judíos de la Free Church OF SCOTLAND}

Alexander Thomson (1820-1899) fue un misionero protestante perteneciente a la Misión de la Free Church of Scotland, una escisión de la Iglesia de Escocia producida en 1843 por desavenencias teológicas con la anterior, la denominada Kirk disruption ${ }^{4}$. De este manera, la nueva

TARragona Borrás y Ángel SÁEnz Badillos [Leiden-Boston-Köln: Brill, 1999] págs. 593-602: 596) destacó la invasión léxica del español moderno en los textos de los misioneros. Según Haim Vidal SePHiнa («The instruction of Judeo-Spanish in Europe», Sophar 19 [2001] págs. 58-70: 64), el lenguaje usado por los misioneros en sus escritos era más bien una representación del judesmo o lengua vernácula oral. Como afirman David Bunis, Joseph CheTrit y Haiden SAHIm («Jewish Languages Enter the Modern Era», en The Jews of the Middle East and North Africa in Modern Times, eds. R. Spector Simon, M. Menachem Laskier, and S. Reguer [New York: Columbia University Press, 2003] págs. 113-141: 121), el lenguaje de los misioneros debe considerarse como una introducción al español moderno para los lectores sefardíes del momento. Una década después, Aitor GARCía Moreno ( ¿iAnte el primer diccionario monolingüe judeoespañol?», Sefarad 73:2 [2013] págs. 371-408: 398) consideró el lenguaje de Thomson como un «español sefardizado». Más recientemente, David M. Bunis («The lexicography of Sephardic Judaism», en International Handbook of Modern Lexis Lexicography, eds. P. HANKs y G.-M. SChryver [Berlin-Heidelberg: Springer, 2017] págs. 1-25: 5) ha afirmado que los textos de los misioneros contribuyeron a la transición del judeoespañol vernacular al español moderno. Por último, Aitor García Moreno ( «Poemas castellanos en textos sefardíes: ejemplos en La escalera a la anveźadura [Constantinopla 1853 y 1888]», Sefarad 78:1 [2018] págs. 149-200: 180, 183 y 199) ha reconocido importantes divergencias lingüísticas de la obra de Thomson con el judeoespañol más castizo, incluso en sus retraducciones.

${ }^{4}$ Fruto de los intentos por parar la difusión de ideas de la Ilustración por parte de algunos ministros de la Iglesia de Escocia, surgió así una facción más evangélica nacida en el seno de los movimientos de avivamiento protestantes iniciados en Cambuslang en Escocia en 1742; vid. Esther BreitenBaCh, Empire, Religion and National Identity: Scottish Christian Imperialism in the 19th and early 20th Centuries (Edinburgh: University of Edinburgh, 2005) pág. 78. El final de este cisma no llegaría hasta 1929 cuando 
iglesia escocesa, de carácter más específicamente evangélico, pasaba a hacerse con gran parte de las estaciones de misioneros que habían puesto en marcha los primeros ${ }^{5}$. Uno de estos casos es la denominada Misión para los judíos, concebida en $1838^{6}$, y de la cual la estación de Constantinopla era parte de su plan para la conversión al protestantismo de esta comunidad. El trabajo evangelista en esta región del Imperio otomano por parte de la Iglesia de Escocia se había iniciado en 1842, cuando se apropiaron del trabajo ya iniciado por la London Jews Society. Tras el cisma, la Iglesia Libre de Escocia se hizo cargo de esta misión, poniendo a un misionero de otra iglesia a cargo, el también protestante Wilhelm Gottlieb Schauffler (1798-1883), padre de dicha estación y, en verdad, empleado por la American Board of Commissioners for Foreign Missions, demostrando el sentimiento de unión y compañerismo entre las diferentes hermandades de religiosos protestantes en la zona. Junto al conocido médico converso judío, el Dr. Leitner, Schauffler abrió una enfermería en el barrio de Hasköy en Constantinopla en 1844. Sin embargo, estos colaboradores cristianos no abandonarían plenamente la misión hasta la llegada de Alexander Thomson en junio de $1847^{7}$.

El misionero escocés autor de los libros que aquí analizamos fue uno de los escritores y traductores más prolíficos ${ }^{8}$ de la Misión de la Iglesia Libre de Escocia dedicada a la conversión de judíos sefardíes en Cons-

ambas denominaciones cristianas se volvieron a unir bajo el paraguas de la Iglesia Unida de Escocia, aunque quedarían hasta hoy en día un pequeño remanente de cristianos evangélicos que han seguido denominándose como Iglesia Libre de Escocia.

${ }^{5}$ Según Norman L. Walker (Chapter from the history of the Free Church of Scotland [Edinburgh-London: Oliphant Anderson \& Ferrier, 1895] pág. 170): «when the Disruption came, all the missionaries without exception joined the Free Church».

${ }^{6}$ En John S. Ross, «An Introduction to Two Thousand Years of Jewish Evangelism», Haddington House Journal 5 (2003) págs. 53-65: 61.

7 En palabras del propio Schauffler, en Edwards A. PARK, (ed.), Autobiography of William. G. Schauffler, for forty-nine years a missionary in the Orient (New York: Anson D. F. Randolph \& Company, 1887) pág. 197: «The German Jews were now under the care of the Scotch missionaries, and I was still hoping to see something efficient done for the Sefardee Jews of Constantinople and of Turkey; but when Mr. (now Dr.) A. Thomson came, and there was no more doubt of the readiness and intention of our Scotch brethren to occupy the Sefardee field, I saw that Constantinople was lost to us».

8 Para una consulta de las obras atribuidas a Alexander Thomson, vid. GARCíA Moreno, «Primer diccionario», págs. 373-374, y «Poemas castellanos», págs. 151-154. 
tantinopla. La función de dichos libros era claramente proselitista, pues Thomson, como muchos de sus correligionarios de la época, tenía como objetivo principal la conversión de este grupo para así adelantar el Reino de los Cielos ${ }^{9}$. Gran parte de la producción escrita de este reverendo protestante tenía un claro carácter educativo ${ }^{10}$ y fue concebida para su uso en las escuelas que los mismos misioneros de la Iglesia habían establecido, como la de Hasköy y la de Gálata ${ }^{11}$. En este contexto se publicó la obra Ele Toledot Bené Yisrael (1854 y 1886).

${ }^{9}$ La obra evangelista de estos misioneros se enmarca dentro de las prácticas milenaristas protestantes. Este grupo de cristianos deseaba el reino milenario de Cristo (una interpretación evangélica de Apo 20:2-7) que para los creyentes post-milenaristas (la corriente más típica entre los protestantes de Gran Bretaña en el siglo XIX) sucedería justamente después de la conversión de los judíos.

${ }^{10}$ Una de las principales estrategias para la conversión de judíos empleadas por los misioneros escoceses de Constantinopla era la educación formal de esta comunidad. Como afirma Betül BAŞARAN (Reinterpreting American Missionary Presence in the Ottoman Empire: American Schools and the Evolution of Ottoman Educational Policies (1820-1908) [Ankara: Bilkent University, 1997] pág. 11), «high rated of illiteracy among Ottoman subjects made the missionaries even more inclined towards education. The ideal of spreading the Gospel required at least simple literacy training».

11 Ambas escuelas formaban a alumnos judíos askenazíes y sefardíes en el aprendizaje de geografía, matemáticas, gramática inglesa y conocimiento general, aunque se hacía un especial hincapié en historia de la iglesia y el catecismo protestante. La escuela de Hasköy, donde Thomson principalmente realizó sus labores como maestro, situada en el barrio homónimo, fue fundada en 1847 por el misionero escocés, pero puso fin a su andadura en 1859 con la retirada de este reverendo para convertirse en el agente de la British and Foreign Bible Society de Constantinopla. La asistencia de alumnos a esta escuela fue siempre muy irregular, de 4 o 5 alumnos a unas pocas decenas, debido a las heremot ('prohibiciones') dictadas por los rabinos contra el centro educativo misionero. La escuela de Gálata tuvo mayor suerte que la de Hasköy, contando con 62 alumnos desde 1845, una cifra que se mantuvo de manera regular durante varias décadas. En definitiva, es importante destacar la labor educativa desempeñada por los protestantes, ya que, como señala Cengiz Sisman («Failed Proselytizers or Modernizers? Protestant Missionaries among the Jews and Sabbateans/Dönmes in the Nineteenth-Century Ottoman Empire», Middle Eastern Studies 51:6 [2015] págs. 932-949: 945), los misioneros fueron los introductores de la educación moderna europea en la comunidad sefardí de Constantinopla. 


\section{ESTUDIO LINGÜÍSTICO}

Alexander Thomson muestra dos períodos de producción en judeoespañol temporalmente diferenciados. El primero se sitúa a inicios de la década de 1850, pocos años después de su llegada a Constantinopla, y constituye el grueso de su producción, cuando el misionero adquiere unas bases mínimas del idioma meta para traducir o escribir libros cuanto menos inteligibles para los judíos sefardíes. Será en este período cuando publique la traducción al judeoespañol aljamiado del famoso libro inglés Dr. Barth's Bible Stories ${ }^{12}$ bajo el título de Ele Toledot Bené Yisrael o Cincuenta y dos cuentos tirados del Arba'á ve'esrim para el uso de escuelas y familias, con grabados (de aquí en adelante ET1854), publicado en Constantinopla en $1854^{13}$ (como se verá en la figura 1). E1 propósito de esta obra era, en principio, educativo, pues tenía como fin fomentar la lectoescritura entre los niños sefardíes asistentes de las escuelas de los misioneros; aunque en verdad el objetivo era claramente proselitista, como el propio reverendo escocés afirmaría tiempo después:

This translation from Dr. Barth's Bible Stories [...] was intended to be read by any Jew without giving offence, as it is confined for the most

12 Traducción realizada por el autor del original alemán Zweymal zwey und fünfzig Biblische Geschichten für Schulen und Familien ['Cincuenta y dos historias tomadas de la Biblia para el uso de escuelas y familias'; mi traducción] (Calw: Johann Ludwig Federhaff, 1832), a saber, el protestante alemán Christian Gottlob Barth (1799-1862). El libro original estaba dividido en dos partes, el Antiguo y el Nuevo Testamento, la primera escrita por Ludwig Georg Hochstetter, quien no pasó a la posteridad como autor tras la apropiación de la autoría del texto de su compañero, como bien nos informa Katrin BINDER, en "A Garland of Stories: Kathamale», en An Indian to the Indians? On the Initial Failure and the Posthumous Success of the Missionary Ferdinand Kittel (18321903), ed. Reinhard WeNDT (Wiesbaden: Harrassowitz Verlag, 2006) págs. 231-255: 233. El texto fuente de la traducción de Thomson era una traducción al inglés denominada Bible Stories for the young, by C. G. Barth, D. D. Old and New Testaments. Translated from the 31th German edition (London: The Religious Tract Society, 1851), comúnmente conocida por su forma abreviada Dr. Barth's Bible Stories. Como se notará en nuestro estudio, tanto la traducción como la retraducción del misionero al judeoespañol eliminan la segunda parte de la traducción al inglés, es decir, obvian la sección neotestamentaria.

${ }^{13} \mathrm{La}$ imprenta elegida por Thomson para la publicación de estos ejemplares era la del periodista nacido en Constantinopla, Alfred B. Churchill (1825-1870), con quien publicó gran parte de su primera producción. 
part to the text of Scripture without note or comment [...]. This little work does not, indeed, to the Jewish mind, as now perverted by tradition, convey the truths of the gospel with degree of prominence; yet we cannot but hope much good from its circulation, as it as least presents the connected narrative of Old Testament History unperverted by the mass of silly traditions with which the Rabbis have encumbered it ${ }^{14}$.

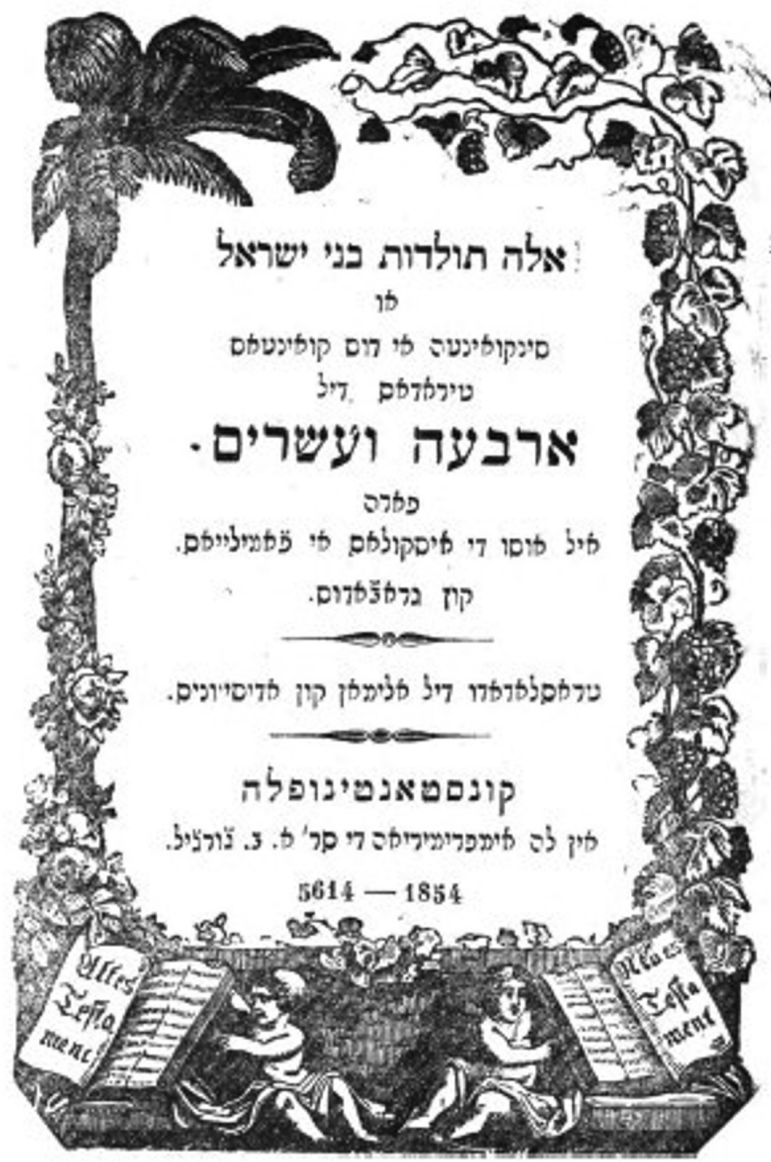

Figura 1. Portada de la traducción del Ele Toledot Bené Yisrael (Constantinopla, 1854)

${ }^{14}$ En The Home and Foreign Record of the Free Church of Scotland, August 1856July 1857. Volumen I New Series (Edinburgh: James Nichol - London: James Nisbet) pág. 206. 
El libro fue después retraducido dos veces, en $1868^{15}$ y en 1886. La figura 2 muestra la portada de este último texto, titulado Ele toledot bené Yisrael; quiere dećir ciento y dieź y siete cuentos tirados del ARBA'Á VE'ESRIM y de las historias antiguas, para el uśo de los yisraelitas protestantes (de aquí en adelante ET1886), también publicado en Constantinopla pero por la imprenta de Arşag Hagop Boyaciyan (1837/91914) ${ }^{16}$.

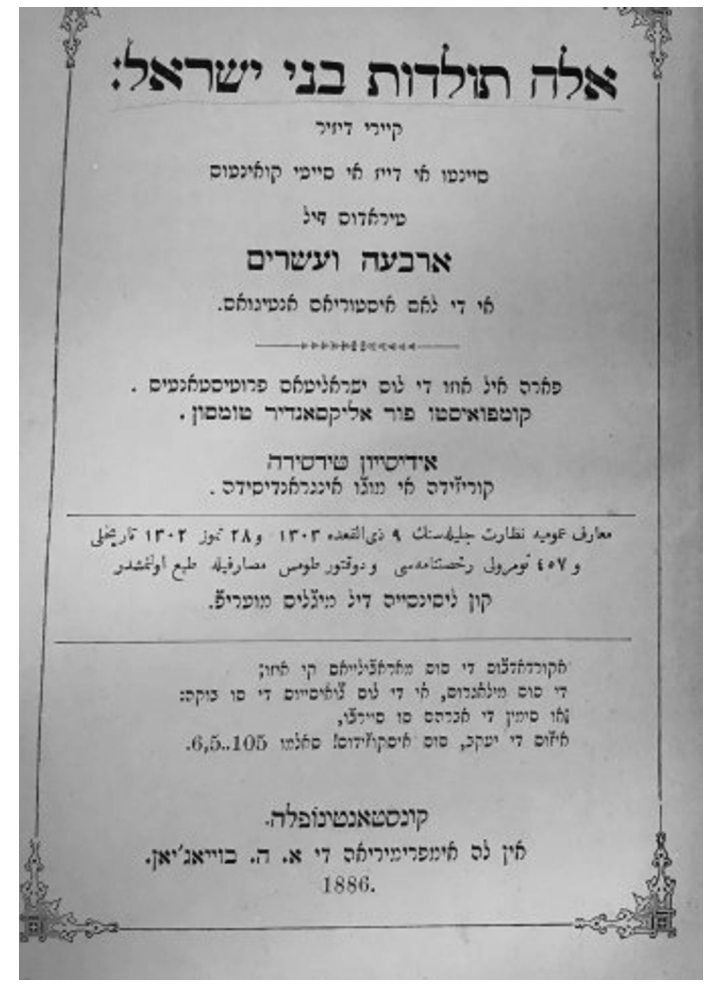

Figura 2. Portada de la traducción del Ele Toledot Bené Yisrael (Constantinopla, 1886)

15 Primera retraducción del misionero a cuyo original no hemos podido aún acceder, pero que consta como localizada en la New York Public Library según se detalla en la Bibliography of the Hebrew Book (1470-1960) de la National Library of Israel.

16 Tras la muerte de Churchill no extraña el cambio a la imprenta de Boyaciyan, pues este era uno de los primeros frutos de los misioneros protestantes americanos, educado en el famoso Robert College de Estambul. 
Pasamos ahora al comentario de algunas de las características lingüísticas más sobresalientes de la primera traducción, seguidas de nuestra explicación de los principales cambios lingüísticos hallados en la retraducción.

\subsection{Características lingüisticas del judeoespañol de Thomson en 1854}

Dividimos esta primera sección en aspectos linguüísticos, señalando cuáles resultan más prototípicos del judeoespañol decimonónico castizo y cuáles lo son menos.

\subsubsection{Aspectos gráfico-fonéticos}

La característica lingüística prototípica del judeoespañol aljamiado más visible adoptada por Thomson se da en el ámbito de la grafemática. La elección de la habitual aljamía hebrea para representar el judeoespañol -y no de las letras latinas- es la particularidad que más resalta en las traducciones de Thomson como parte de su estrategia de convergencia a la prototipicalidad del judeoespañol decimonónico. Por un lado, los títulos, tanto del propio libro como de cada historia en él contenida, se escriben en letra cuadrada o merubá . Por otro lado, la narración de cada historia se presenta en la grafía habitual de los textos sefardíes aljamiados, conocida como raší. Asimismo, estos textos se caracterizan por el uso de matres lectionis, es decir, el recurso a signos gráficos consonánticos en hebreo (álef $\langle\boldsymbol{N}\rangle$, yod $\langle>>$, vav $\langle 1\rangle$, y $h e<ה>$ ) para representar vocales (/a/, /e, i/, /o, u/ y /-a/, respectivamente). Especial atención merecen las particularidades que resalta García Moreno en su artículo sobre El catecismo menor (Constantinopla, 1854) ${ }^{17}$, quien concluye que la grafía usada por el misionero en judeoespañol viene determinada en buena medida por aquella del español moderno y ciertas elecciones de grafías realizadas por Thomson muestran una gran dependencia del español peninsular del momento más que del propio judeoespañol.

\footnotetext{
17 Vid. García Moreno, «Primer diccionario», págs. 398-399.
} 
En el plano fonético, los primeros textos del misionero ya reproducen fenómenos prototípicos del judeoespañol: el seseo, el yeísmo, la neutralización de oposición entre vibrante simple /r/ y múltiple $/ \mathrm{rr} /$, realizada presumiblemente como [r] en la mayoría de los casos; la distinción entre la labial sonora oclusiva /b/ y la fricativa /v/; el desarrollo de una velar oclusiva sonora $/ \mathrm{g} /$ ante el diptongo [we-] en inicial de palabra, como en גואירטו / güerto en vez del español huerto; la palatalización de [s] antepuesta a la velar oclusiva sorda [k], así como en la desinencia verbal de 2. ${ }^{a}$ persona de plural: otro fenómeno que parece haberse adquirido en esta etapa, aunque de forma parcial, como explicaremos más detalladamente en la sección 3.2.1.

\subsubsection{Aspectos morfosintácticos}

Presentamos ahora una selección de los aspectos morfosintácticos más llamativos de la producción de la década de 1850, representados principalmente en ET1854. Entre ellos describiremos algunos usos particulares que afectan a los artículos, a las formas verbales, al uso de preposiciones, a la ordenación adjetivo-sustantivo, a la aparición de sujetos explícitos, a la falta de concordancia entre sujeto y verbo y al uso de ciertas oraciones subordinadas.

\subsubsection{Sintagma nominal Dios $\sim$ Dio precedido de artículo}

El uso de determinantes por parte del traductor no es especialmente llamativo si no fuera por el peculiar uso de Thomson del sintagma nominal para referirse a Dios. Por un lado, Thomson respeta la prototípica reducción consonántica del nombre $<-s>$ en judeoespañol y se refiere a este como Dio. Sin embargo, el misionero obvia el uso del artículo determinado que se utiliza para este nombre. De este modo, el sintagma nominal Dio parece un híbrido de la forma española (Dios) y la judeoespañola (el Dio). 


\subsubsection{Formas verbales}

En primer lugar, el traductor escocés parece usar la forma prototípica sefardí para la desinencia de $1 .^{\mathrm{a}}$ persona del pretérito perfecto simple $\{-1\}$ para verbos terminados en $\{-a r\}$. Siendo que la yod final $<>->$ de estas formas bien pudiera ser entendida tanto $\{$-é\} como $\{-1\}$ en el singular, tenemos que recurrir a la forma plural para saber qué opción prefiere. La clave está en la forma empleada para la $1 .^{\mathrm{a}}$ persona de plural, pues encontramos una yod $<->->$ y no una álef $<-\boldsymbol{N}$->; por ejemplo, tornimos (טורנימוס) en vez de tornamos (טורנאמוס). De este modo, podemos leer que el misionero produce el uso prototípico en judeoespañol para estas formas verbales.

No obstante, no parece que reproduzca los usos castizos de las formas de $1 .^{\text {a }}$ persona de singular de presente de verbos como ser o estar, só (סו) y estó (איסטו) en judeoespañol. Thomson los escribe siempre a la española, es decir, soy (סויי) o estoy (איסטויי). Dicho sea de paso, posiblemente por interferencias del inglés, el misionero a veces no parece distinguir el verbo ser de estar, a veces también confundiéndolos con el verbo haber, como mostraremos en la sección 3.2.2.4. Además, Thomson respeta la palatalización de la consonante $<-s\rangle$ final pero obvia la absorción de la semivocal postónica de los verbos en $2 .^{a}$ persona del plural de presente y futuro. De este modo, lo normal es que use siempre formas terminadas en <-áiš o -éišs> como en estáiš (איסטאייש) o comeréiš (קומירייש) en vez de las sefardíes <-áš o -éśs como en estás (איסטאש) o comeréš (קומיריש).

Mención aparte merecen el uso continuo de formas consideradas vulgarismos en español pero no así en judeoespañol; por ejemplo, haiga en lugar de haya. Además, Thomson utiliza el empleo de participios de presente como hacién, andán, asentán, estudián, aỵolán o juzźgán, también comunes en los ladinamientos bíblicos.

\subsubsection{Uso de preposiciones}

El origen de los problemas con el uso de preposiciones que hallamos en ET1854 bien podría deberse a interferencias del inglés o bien dificul- 
tades en la diferenciación del español normativo y judeoespañol decimonónico, el cual no siempre coincide en usos y formas con los del español peninsular de la época. Por un lado, encontramos numerosos casos de queísmo en textos como los siguientes, donde el traductor omite la preposición previa a la conjunción que.

«Antes $[d e] q u e^{18}$ Dio crió, afuera de Dios miśmo non hubo nada» (ET1854: 1).

«Hasta tal bajeźa pudo decender un noble rey después [de] que se había tirado de él el espíritu de Dio» (ET1854: 107).

Por otro lado, Thomson parece tener problemas con características como humanidad y animacidad ligados al complemento directo. El misionero es incapaz de distinguir si procede añadir el marcador preposicional $a$, aunque normalmente lo obvia para referirse a humanos y no a objetos:

«Echa [a] esta sierva afuera con su hijo» (ET1854: 20).

«[...] no quiso reconocer $a$ los servicios de Yosef» (ET1854: 51).

Otro problema que encontramos en los textos de la primera etapa de producción es la confusión de la preposición para marcar destino, pues es normal que utilice la preposición en cuando bien debiera ser $a$, como en el siguiente ejemplo:

«Y ansí los enṿió en la cárcel» (ET1854: 42).

Thomson también es proclive a introducir infinitivos con la preposición de, algo que no se corresponde necesariamente con el judeoespañol castizo:

«Estas fiestas los judiós bušcan de guardar hasta hoy según la ordenanźa de Mošé» (ET1854: 77).

Por último, no es raro que el autor de estos textos también confunda, como suele darse en casos de aprendices anglófonos de español, las preposiciones para y por:

«[...] y enviió Yosef por su padre carroźas» (ET1854: 47).

\footnotetext{
${ }_{18}$ Resaltaremos en cursiva aquellos aspectos que deben considerarse en este y sucesivos casos.
} 


\subsubsection{Orden adjetivo-sustantivo}

Mencionamos este aspecto por su importancia en el análisis de García Moreno con respecto a El catecismo menor (Constantinopla, 1854). Dicho estudio presenta numerosos ejemplos de una ordenación adjetivosustantivo un tanto anómala y más bien propia de la interferencia del inglés probablemente causada por la traducción directa del texto original al judeoespañol. De esta manera, encontramos una distribución calco del inglés en expresiones como principal fin (del inglés chief end), particular hecho (del inglés special act) o semanal sábado (del inglés weekly Sabbath) entre otros muchos casos citados en aquel artículo. En ET1854 no es tan común esta distribución en los sintagmas nominales, aunque a veces aparecen casos que también son llamativos al respecto como $s a$ biduría tanta.

\subsubsection{Sujetos explícitos}

Posiblemente por la influencia del inglés, donde solamente los verbos en $3 .^{a}$ persona del singular del presente simple tienen una desinencia marcada, motivando la necesidad del sujeto para conocer el sujeto del verbo, los textos de Thomson parecen redundar más en el uso de sujetos explícitos. El misionero es por tanto más proclive a traducir los sujetos de manera explícita de lo que se esperaría en una traducción de un nativo de español o judeoespañol. Los siguientes casos muestran esta inclusión del sujeto explícito en oraciones donde contextualmente se da por sabido el hacedor de la acción verbal:

7).

«Cuando tú labrares la tierra, non te dará más su fuerźa» (ET1854:

«[...] porque agora ya supe que tú temes a Dio» (ET1854: 22).

«Oyó también que el rey había prometido que quién hubiera matado al gigante, él recibiría por mujer la hija del rey [...]» (ET1854: 103). 


\subsubsection{No concordancia entre sujeto y verbo}

Esta característica bien puede deberse a la influencia del hebreo o a la simple interpretación del sujeto como entidad plural cuando este es un colectivo, como en inglés:

«La meźclada plebe entre ellos empeźaban a desear carne, lloraban y dolían uno con otro» (ET1854: 79).

«El pueblo quisieron hacerlo rey» (ET1854: 93).

\subsubsection{Uso de oraciones subordinadas}

Thomson, como todo aprendiz anglófono de (judeo)español, tiene problemas con el uso de las oraciones subordinadas y los verbos en subjuntivo. En los siguiente ejemplos leemos la confusión del modo verbal en las oraciones subordinadas:

«Todo el que me halla me matará» (ET1854: 7).

«[...] se atrevió hasta tomar el espantośo consejo de matar todos los machos niños de los hebrreos que nacerían [...]» (ET1854: 52).

\subsubsection{Aspectos léxicos}

E1 léxico en los textos escritos o traducidos por los misioneros protestantes se caracteriza por una fuerte influencia del castellano ${ }^{19}$. Como García Moreno (2013) señala, el estudio del léxico de la primera etapa de producción de Thomson materializado en El catecismo menor (Constantinopla, 1854) demuestra que dicha traducción combinaba por igual neologismos del español contemporáneo como apetito (en vez del sefardí apetite) o contentos (en vez del sefardí contentes) e intentos de introducción de vocabulario castizo como afalagar, enšalžamiento, esyiblamiento, firmamiento, folor, preba o regmidor ${ }^{20}$. Estos últimos ítems denotan un esfuerzo voluntario por parte del traductor de buscar

\footnotetext{
19 Vid. Quintana RodríGuez, «Proceso de recastellanización», pág. 595.

20 Vid. García Moreno, «Primer diccionario», pág. 400.
} 
vocablos ora castizos ora antiguos provenientes de ladinamientos bíblicos como anyéźanos, fruchiguávos, hinchid, meldadura, muchiguávos, peje, preniśma o sojigualda. De hecho, futuros estudios léxicos podrían estudiar hasta qué punto el misionero podía distinguir ladinamientos de vocabulario castizo.

Otra categoría léxica que prima en la traducción de ET1854 son los préstamos, especialmente hebraísmos. El misionero principalmente los toma para nombres propios de origen hebreo como por ejemplo Adonay

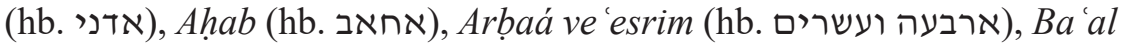

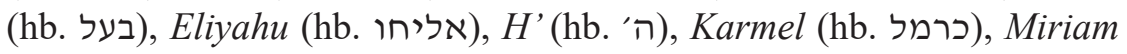
(hb. מרים), מטן (מרן), Satán (ha'acob (hb. יעקב), Yisrael (hb. ישראל), Yešúa (מישוע) y Yohanán (hb. יוחנן) entre otros. Además, el misionero incluye otros hebraísmos para ciertas figuras, conceptos y lugares en el judaísmo como amén (hb. אמן 'amén'), darom (hb. דרום 'sur'), kehuná (hb. כהונה 'sacerdocio'), kohén (hb. כהן 'sacerdote'), kohén gadol (hb. כהן גדול 'sumo sacerdote'), Mašíạ (hb. משיח 'Mesías'), Par ' פרעה 'faraón'), safón (hb. צפון 'norte') y yardén (hb. ירדן 'Jb') 'jardín'). Por otro lado, no será raro encontrar hebraísmos en plural, con desinencia <-im> a la hebrea, como es el caso de Ba'alim (hb. מעלים, plural de Ba'al), kerubim (hb. כרבים 'ángeles'), makabim (hb. ספרים 'macabeos') y sefaradim (hb. ספרדים 'judíos sefardíes'). Fruto de esta mezcla de léxico judeoespañol, hebreo y español moderno, no es de extrañar que Thomson incluya híbridos léxicos. Curiosamente, estos van asociados a gentilicios como 'amonitas (עמוניטאס), en vez del español amonitas o el hebreo עמונים / 'amonim; kašdeos (כשדיאוס), en lugar del español caldeos o el hebreo כשדים / נכבים אašdim; ninvitas (נכויטאס), en vez del español ninveos o el hebreo נינבים / פלשים / פלשתיאוס), en vez del español filisteos o el hebreo פלשתים/pelištim; y šomroneos / שומרונים (שומרונאוס), en vez del español samaritanos o el hebreo šomronim.

Por otro lado, la producción de esta época se caracteriza también por la existencia de turquismos no presentes en ET1854 pero sí en obras como La escalera a la anyeźadura (Constantinopla, 1853). Este es el caso de cafeses (tc. sg. kafes 'jaula'), caic (tc. kaylk 'barco'), caravanseray (tc. kervansaray 'caravasar'), chiźmes (tc. sg. çizme 'bota'), hanes (tc. sg. han 'posada', aunque refiriéndose a 'edificio'), maḥmuź 
(tc. mahmuz 'espuela'), parmaques (tc. sg. parmak 'dedo', aunque refiriéndose a parmaklık 'valla'), pašalic (tc. paşalik 'principal división administrativa del Imperio otomano'), quiertenquieler (tc. kertenkele 'lagarto'), sirás (tc. sg. sıra 'línea') y ŷmí (tc. cami 'mezquita').

Hablando de extranjerismos, las interferencias del inglés están bastante presentes en la producción del misionero de la década de 1850 . García Moreno enfatiza ya esta influencia haciendo mención a neologismos como soberanidad (del inglés sovereignity) ${ }^{21}$. De hecho, los falsos amigos son comunes en este período; por ejemplo, largo (del inglés large en la expresión largo tiempo), ordinaria (del inglés ordinary en la expresión ordinaria edad) y sensibles (del inglés sensible como en la expresión señales sensibles). Estas interferencias también afectan a locuciones preposicionales como debajo del poder de Antiohos (del inglés under the power of Antiochus) o construcciones como persiguió detrás (del inglés pursued after), Dio también atrás (del inglés He also gave back) o siete veces más de lo que usaba encenderse (del inglés used to be lighted). Algunas interferencias del inglés son claramente traducciones literales del original de Barth; por ejemplo, cama de muerte (del inglés dying bed), desastres públicos (del inglés public disasters) o se determinaron (del inglés were determined).

Por último, en el plano léxico de la producción de 1850, no queremos soslayar, aunque no sea una característica muy aparente en ET1854, la consecuencia más inmediata de la introducción de neologismos en el plano ideológico. Por ejemplo, existen ciertos vocablos con un claro énfasis protestante que sí introducen nuevos significados para los lectores sefardíes a pesar de no poseer formas nuevas en judeoespañol. La palabra más representativa de esta categoría sería besorá (בשורה "noticia'), que en la obra de Thomson no es una simple noticia, como sería en judeoespañol, sino una buena nueva, la del evangelio de Jesucristo. Entre otras de estas palabras a las que Thomson confiere un nuevo significado más protestante podríamos añadir convertir, devdas, gracia, merecidos, reino de la gracia, salvante y santificar. Todas estas palabras suponen acepciones en cierta medida novedosas para el lector sefardí de la época, pues enfatizan conceptos teológicos protestantes relacionados

21 Vid. García Moreno, «Primer diccionario», pág. 401. 
como la salvación y la gracia salvadora de Cristo más que la propia definición característica en este idioma.

\subsection{Principales cambios en el judeoespañol de Thomson en 1886}

Pasamos ahora a analizar los cambios más significativos en el judeoespañol que leemos en la segunda etapa de producción del misionero a través de la retraducción de Ele Toledot Bené Yisrael a mediados de la década de 1880. Siguiendo la estructura de la sección anterior, nos proponemos comentar primeramente cambios en el nivel gráfico-fonético, seguido del morfosintáctico y, por último, el léxico. Pondremos especial atención ahora a la traducción al judeoespañol del Antiguo Testamento 22 del misionero escocés James Christie (1835-1913). La colaboración de Alexander Thomson en esta traducción pudo haber dejado huella en el idioma que leemos en ET1886, puesto que ambas ya compartían un contenido similar, es decir, historias bíblicas antiguotestamentarias.

\subsubsection{Aspectos gráfico-fonéticos}

El estudio de la grafemática que leemos en la retraducción de ET1886 parece indicar una mejor comprensión de cómo funciona el sistema fonético castizo en el judeoespañol decimonónico. Esta mejora se puede mostrar por medio de una serie de cambios vistos en el texto de la segunda época de producción que parecen acercarse más al sistema gráfico-fonético del judeoespañol.

En primer lugar, como anteriormente habíamos señalado, Thomson no parecía haber entendido cómo funcionaba el seseo en judeoespañol. Cada palabra que contuviera $<\mathrm{z}>$ en español peninsular era representada por el misionero con záyin $<\uparrow>$ en la primera traducción, sin diferenciar nunca si los hablantes sefardíes pronunciasen una fricativa alveolar sonora o sorda. Sin embargo, en la retraducción ya no parece basar su elección de grafema en la grafía del español peninsular y sabe distinguir

22 Séfer Torá, Nebiím veKetubim / El libro de la Ley, los Profetas y las Escrituras, traśladado en la lengua española (Constantinopla: A. H. Boyaciyan, 1873). 
ambos fonemas, reproduciendo el seseo de una manera más apropiada. De esta manera, el misionero cambia adecuadamente el grafema záyin $\langle\uparrow\rangle$, que reproduce el sonido fricativo alveolar sonoro [z], cuando su uso era inadecuado en algunas palabras, pues la pronunciación prototípica en judeoespañol era la de su par sordo [s], representado con sámej $<>$. Este es el caso de caźar (קאזאר), cambiado a cazar (קאסאר); coraźón (קוראזון), cambiado a corazón (פוראסון); (פיואירזה), (קסון), cambiado a fuerza (פ'ואירסה), como también puede leerse en la traducción de Christie.

En segundo lugar, de manera inversa al caso anterior, también en su primera etapa, Thomson era proclive al uso de sámej $\langle\nabla\rangle$ cuando la grafía en español peninsular se correspondía con $\langle\mathrm{s}, \mathrm{c}>$, nunca $<\mathrm{z}>$ (antes reservada para záyin $<\uparrow>$ ), para representar el sonido dental fricativo [ $\theta$ ] o la fricativa alveolar sorda [s]. El misionero corrige en la retraducción aquellos casos donde la grafía del español peninsular primaba sobre la pronunciación castiza del judeoespañol, de modo que cambia sámej $\langle\nabla\rangle$ por záyin $\langle\uparrow\rangle$ cuando la primera había sido usada erróneamente. Este es el caso de abismo (אביסמו), que pasa a escribirse como abiśmo (אביזמו); aceite (אסייטי), que pasa a escribirse como aćeite (אזייטי); o adjetivos terminados en <-oso> como espantoso (איספאנטוסו), que pasan a escribirse como espantośo (איספאנטוזו). Cabe mencionar que Thomson no es siempre fiel a las grafías empleadas en judeoespañol por Christie y solamente parece emular la grafemática de Christie en cuanto a los adjetivos en $\langle-o s o\rangle$, escritos por aquel de la misma manera que en culpośo (קולפוזו). Sin embargo, los misioneros difieren a la hora de escribir otras palabras como abiśmo, que Thomson escribe con záyin (אביזמו) pero Christie con sámej (abismo / אביסמו).

En tercer lugar, el misionero deja de usar en su retraducción la grafía záyin con tilde $\left\langle r^{\prime}\right\rangle$, que representa el sonido fricativo postalveolar sonoro [3], para representar los grafemas peninsulares $<\mathrm{g}, \mathrm{j}>$. En la década de 1880 el misionero cambia dicho grafema por $̌$ sin $\langle\boldsymbol{U}\rangle$ para reproducir el sonido fricativo post-alveolar sordo [S], como se espera en judeoespañol en dichos contextos. Este es el caso de palabras como aflojar (אפ'לוז'אר), que Thomson cambia a aflojar (אפר) (באר), bajar (באז'אר), que pasa a bajar (באשאר); (בינדיז'ו), bendijo cambiada a bendijo (דינדישו); (דיז׳ו), que pasa a dijo (דישו). Relacionado a estos casos, 
es curioso el cambio que introduce el misionero en la retraducción al añadir una álef $\langle\boldsymbol{N}\rangle$ como soporte vocálico entre shin $\langle\boldsymbol{U}\rangle$ y $v a v\langle ו\rangle$ para la $3 .^{\text {a }}$ persona del singular del pretérito perfecto simple del verbo dejar (deǰó / דישאו), lo cual no se corresponde con el uso prototípico en judeoespañol. En todos estos casos descritos podemos ver la huella de Christie como modelo, al que sigue Thomson al pie de la letra, incluso en esa forma no prototípica del pasado del verbo dejar (deǰó / דישאו).

En cuarto lugar, aunque muchísimo menos frecuente que los cambios anteriores, vemos que Thomson utilizaba en su primera etapa sámej $\langle\nabla\rangle$, en correspondencia con la letra $<\mathrm{c}>$ del español, para los numerales doce (דוסי), doceno (דוסינו) y trece (טריסי). En la retraducción el misionero optará por un cambio que le acerca al judeoespañol castizo, pues cambia dicho grafema por guímel con tilde $\left.<^{\prime} \lambda\right\rangle$, reproduciendo así el prototípico sonido africado post-alveolar sefardí [d3] para estos casos. De esta manera, estos numerales pasan a escribirse en la segunda etapa como doce (דוג׳י), doĉeno (דוג׳ינו) y treĉe (טריג'י). Una vez más se ve aquí la posible impronta de Christie, quien también escribe estas palabras de la misma manera.

En quinto lugar, Thomson también cambia los grafemas para la 3. ${ }^{a}$ persona del singular del pretérito perfecto simple del verbo querer. En ET1854, la forma que se registra es quiso, con sámej $\langle\nabla\rangle$, fricativa alveolar sorda [s], hasta once veces. El misionero también escribe quiśo con záyin $\langle\uparrow\rangle$, representando la fricativa alveolar sonora $[\mathrm{z}]$, en tres ocasiones. Sin embargo, ya en ET1886 no se registra ninguno de estos grafemas sino que Thomson ahora se decanta por el uso de záyin con tilde $\left\langle\boldsymbol{r}^{\prime}\right\rangle$, fricativa post-alveolar sonora [3]. Es decir, pasamos de quiso (קיסו) o quiśo (קיזו) a quis̀o (קיזו), un cambio que demuestra la conciencia fonética de Thomson, pues parece que esta alteración se corresponde con la forma más usada en el judeoespañol de la época, como refleja el Corpus Histórico Judeoespañol (CORHIJE) ${ }^{23}$ así como con el uso dado por el traductor escocés Christie en 1873.

Por último, al igual que en la traducción de Christie, parece que Thomson al fin ha adoptado el uso de los signos de exclamación e in-

23 Aitor García Moreno y Francisco Javier Pueyo Mena, Corpus Histórico Judeoespañol - CORHIJE (2013-, recurso en línea accesible en $<$ http://recursos.esefardic. es/corhije> [consultado el 1 de octubre de 2019]). 
terrogación tanto al inicio $<\dot{i}, i>$ como al final $<$ ?, ! $>$ de las oraciones exclamativas e interrogativas, y no solo al final de estas.

\subsubsection{Aspectos morfosintácticos}

Procedemos ahora a comentar una selección de los cambios morfológicos y/o sintácticos más llamativos en la producción de la década de 1880. Entre estos se encuentran el sintagma nominal Dios Dio precedido de artículo, las desinencias verbales de segunda persona del plural, las formas de imperativo, las formas y usos de los verbos ser, estar y haber, la confusión entre tiempos perfectos e imperfectos, el uso de preposiciones, sujetos explícitos, el uso del subjuntivo y la elección de nexo para las oraciones subordinadas temporales.

\subsubsection{Sintagma nominal Dios $\sim$ Dio precedido de artículo}

En primer lugar, en la primera etapa como traductor, Thomson empleaba una forma híbrida entre español y judeoespañol para referirse a Dio, a saber, sin el artículo determinado pero con la forma reducida sin $<-s>$ final como señal de respeto. Para la edición de ET1886, vemos este error subsanado siempre, corrigiendo el híbrido, que no era ni español (Dios) ni judeoespañol (el Dio). Como era de esperar, la forma leída en la retraducción se corresponde con la escrita por Christie en su traducción de la Biblia:

«Dio crió los cielos y la tierra por su palabra» (ET1854: 1).

«El Dio crió los cielos y la tierra por su palabra» (ET1886: 5).

«En el principio crió el Dio los cielos y la tierra» (Gén 1:1).

\subsubsection{Desinencias verbales de $2 .^{\mathrm{a}}$ persona del plural}

La retraducción de ET1886 muestra una reducción del diptongo <-áiš,

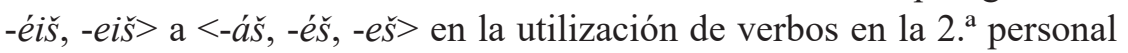
del plural de presente o futuro. En ET1854 advertimos que Thomson era 
consciente de la palatalización de la sibilante final en estas formas verbales, como era común en la lengua sefardí. Sin embargo, el traductor utilizaba un diptongo antepuesto a la palatalización, impropio ya en judeoespañol. Como se ejemplifica ahora, el reverendo ha rectificado todos estos usos en ET1886, asemejándose así más a la forma escrita por Christie:

«Por esto vos prebaré si estáiš [איסטאייש] hablando verdad o no» (ET1854: 41).

«Por esto vos prebaré si estáš [איסטאש] hablando verdad o no» (ET1886: 57).

«[...] ¿Por_qué estáš mirando el uno al otro?» (Gén 42:1) 24 .

«Y ansí lo comeréiš [קומיריש] [...]》(ET1854: 60).

«Y ansí lo comeréš [קומיריש] [...]» (ET1886: 91).

«Y ansí lo comeréš [קומיריש] [...]» (Éx 12:11).

\subsubsection{Formas de imperativo y perífrasis de obligación}

En tercer lugar, en lo que respecta a la morfología verbal, Thomson añadirá la consonante $\langle-d\rangle$ antes del pronombre clítico final en imperativos. Este cambio no se corresponde con los usos del judeoespañol castizo, por lo que se entiende que no lo aprende de la lengua sefardí de la época. Es muy probable que Thomson tome esta forma de Christie, quien también la utiliza en su traducción de 1873:

$$
\begin{aligned}
& \text { «Llegavos [לייגאב'וס] agora a mí» (ET1854: 46). } \\
& \text { «Llegadvos [לייגאדב'וס] agora a mí» (ET1886: 61). } \\
& \text { «Allegadvos [אלייגאדב'וס] agora a mí» (Gén 45:4). }
\end{aligned}
$$

Por otra parte, también en relación a formas verbales, el misionero introduce más ejemplos de perífrasis de obligación prototípica de los ladinamientos bíblicos, al igual que el otro traductor escocés:

\footnotetext{
${ }^{24}$ Se ha tomado un versículo cercano a la historia narrada. Se elige aquí otro versículo diferente al que muestran los ejemplos homónimos de ET1854 y ET1886 porque el verbo empleado en la traducción bíblica de Christie no es el mismo y no serviría como buen ejemplo de comparación.
} 
«De todos los árboles del güerto libremente come; ma del árbol del saber bien y mal non comerás; porque en el día de tu comer de él, por cierto morirás» (ET1854: 3).

«De todo árbol del güerto comer comerás; ma del árbol del saber bien y mal no comas de él; porque en el día de tu comer de él, morir morirás» (ET1886: 8).

«De todo árbol del güerto comer comerás; ma del árbol del saber bien y mal no comas de él; porque en el día de tu comer de él, morir morirás» (Gén 2:16-17).

\subsubsection{Formas y usos de ser, estar y haber}

La retraducción de ET1886 no implica cambio alguno en cuanto a las formas de la 1. a persona de los verbos ser y estar. El misionero sigue empleando estas voces del español peninsular, soy / סויי y estoy / סיסטויי, en vez de las comúnmente empleadas en judeoespañol, so / ס y estó / איסטו. Como no es de extrañar, ambas formas son las empleadas en la traducción de Christie de 1873:

«Yo soy tu mamparo» (ET1886: 34).

«[...] Yo soy tu mamparo [...]» (Gén 5:1).

«¡Déj̆ame gustar de aquel bermejo porque estoy cansado!» (ET1886: 44).

«[...] Te rogo que me des a comer de este bermejo, este bermejo, porque estoy cansado!» (Gén 25:30).

Por otro lado, el reverendo escocés parece mejorar en la elección de los verbos ser, estar o haber, y no los confunde tanto como en la primera traducción. Aunque a decir verdad, todas estas supuestas mejoras podrían corresponderse con cambios para emular la traducción de Christie, como bien revelan los siguientes ejemplos:

«[...] como antes cuando tú estabas su escaciano» (ET1854: 37).

«[...] cuando eras su escanciano» (ET1886: 54).

«[...] cuando eras su escanciano» (Gén 40:13).

«iVivo H', Dio de Yisrael, que me paró delantre de él, que non será rocío ni lluvia en estos años [...]» (ET1854: 131).

«iVivo H', Dio de Yisrael, delante del cual yo estoy, que no habrá rocío ni luvia en estos años [...]» (ET1886: 180). 
«iVivo H', Dio de Yisrael, delante del cual yo estoy, que no habrá rocío ni luvia en estos años [...]» (1Re 17:1).

Sin embargo, en muchos otros casos Thomson no parece seguir el ejemplo de Christie, lo que le acarrea diversos errores en su traducción:

«[...] a la puerta yaće el pecado, y a ti estará su deśeo» (ET1886: 14).

«[...] a la puerta yaće el pecado, y a ti será su deśeo [...]» (Gén 4:7).

«Afuera de estos, había los preśentes de los primogénitos de los animales limpios» $(\text { ET1886: 105 })^{25}$.

«[...] y vuestros hijos pastores serán en el deśierto cuarenta años» (ET1886: 120).

«Y vuestros hijos andarán ${ }^{26}$ errando en el deśierto cuarenta años [...]» (Núm 14:33).

«[... ] y cuando fue caliente el sol, se secaron sus hojas» (ET1886: 199).

«[...] y hirió la calabacera y se secó» (Jonás 3:7).

\subsubsection{Confusión entre tiempos perfectos e imperfectos}

Una vez más, la última retraducción nos enseña tintes de mejora con respecto a la confusión entre tiempos perfectos e imperfectos que caracterizaban a la primera traducción del misionero. Sin embargo, la corrección de estos casos no es plena en la década de 1880. El último ejemplo demuestra que, como en algunas otras ocasiones, el misionero no parece adoptar a veces el modelo de la traducción de Christie, produciendo una forma malsonante:

$$
\begin{aligned}
& \text { «iNingún estraño podía estar allí» }(E T 1886: 60)^{27} \text {. } \\
& \text { «[...] porque no supieron qué cośa fuera» }(\text { ET1886: 95). } \\
& \text { «[...] porque no sabian qué era» (Éx 16:15). }
\end{aligned}
$$

25 Este texto no es un versículo comparable con la traducción de Christie.

26 Aunque el verbo empleado por Christie sea diferente, el traductor escocés reconoce en un comentario a esta traducción que la expresión en hebreo sería serán pastores, lo que puede haber motivado la traducción de Thomson.

27 El ejemplo aquí presentado no se puede comparar con la traducción de Christie al ser un comentario al texto bíblico de Gén 45:1. 


\subsubsection{Uso de preposiciones}

Thomson sigue teniendo dificultades con el uso de las preposiciones en la retraducción. El misionero aún duda de si usar la preposición $a$ antes del Complemento Directo con la característica [+humano]. De nuevo, el misionero escocés no parece tener en cuenta aquí el modelo lingüístico de Christie:

$$
\begin{aligned}
& \text { «Echa }[a] \text { esta sierva afuera con su hijo» (ET1886: 38). } \\
& \text { «Echa } a \text { esta esclava y a su hijo» (Gén 21:10). } \\
& \text { «[...] que no conoció } a \text { Yosef [...]» (ET1886: 84). } \\
& \text { «[...] que no conocía } a \text { Yosef» (Éx 1:8). }
\end{aligned}
$$

Además, parece que Thomson no termina de corregir otros problemas típicamente asociados a aprendices de español como la diferencia entre para y por, para lo que tampoco parece fijarse en la traducción de Christie:

«[...] y enviió Yosef por su padre carretas» (ET1886: 61).

«[...] tomad para vośotros de la tierra de Ayifto carretas para vuestros niños [...]» (Gén 45:19).

\subsubsection{Sujetos explícitos}

En este punto observamos una característica que hace al texto más sefardí y menos producto del inglés, pues ET1886 contiene menos sujetos explícitos que ET1854. El traductor lleva a cabo ciertas omisiones de sujetos innecesarios, como en el siguiente ejemplo. Dicho sea de paso, una vez más, pudiera aquí leerse la impronta de su compañero escocés, quien también obvia ciertos usos de sujetos explícitos en algunos textos como el siguiente:

«Cuando tú labrares la tierra, non te dará más su fuerźa» (ET1854: 7).

«Cuando labrares la tierra, no te dará más su fuerza» (ET1886: 14).

«Cuando labrares la tierra, no te dará más su fuerza $[\ldots] »(G e ́ n$ 4,12). 


\subsubsection{Uso de subjuntivo}

Thomson parece mejorar en cuanto a la traducción del subjuntivo se refiere en ET1886, por lo que en muchos casos veremos correcciones sobre usos leídos en la traducción anterior, como es el siguiente caso cuya forma no varía de la dada por Christie:

«Todo el que me hallare me matará» (ET1886: 84).

«[...] cualquiera me topare me matará» (Gén 4:14).

Sin embargo, la retraducción no siempre mejora la primera traducción. Curiosamente, cuando Thomson no puede usar la traducción de su compañero como modelo, como con el texto de Éx 1:22, el misionero es incapaz de alterar su traducción previa:

«[...] uno de los reyes aun se atrevió hasta tomar el espantośo consejo de matar todos los machos niños de los hebreos que nacerían $[\ldots]$ » (ET1854: 52).

«[...] se atrevió aun a formar el cruel consejo de matar todos los machos niños de los 'eḅreos que nacerían [...]» (ET1886: 84).

«Y Par'ó encomendó a todo su pueblo dićiendo: "Todo hijo que naciere lo echaréš en el río y toda hija aṿidiguaréš"» (Éx 1:22).

\subsubsection{Nexo en subordinadas temporales}

Para terminar con esta sección, cabe destacar el cambio de nexo usado por Thomson en las construcciones subordinadas temporales introducidas por como. En ET1886, el traductor recurre a la sustitución de como por cuando o a cualquier otro tipo de formulación para introducir este tipo de oraciones. A veces estos cambios se corresponden además con el modelo lingüístico aportado por Christie:

«Como estaba Abram agora de los noventa y nueve años, se le apareció el Señor [...]» (ET1854: 15).

«Cuando era Abram de noventa y nueve años, se le apareció H' [...]» (ET1886: 34).

«Y cuando fue de edad de noventa y nueve años, se apareció H' a Abram [...]» (Gén 17:1) 
Si bien otras veces Thomson seguirá su propio criterio, sin seguir literalmente la traducción del otro escocés, como vemos en:

«[...] esclamaron los once hijos como llegaron cerca de su padre» (ET1854: 47).

«[...] esclamaron los hijos en llegándose a su padre» (ET1886: 61).

«Y subieron de Ayifto y vinieron a la tierra de Kena án a Ya'acob su padre» (Gén 45:25).

\subsubsection{Aspectos léxicos}

ET1886 se caracteriza por la inclusión de sustituciones léxicas que hicieron de esta nueva edición un texto mucho más sefardizado ${ }^{28}$. La paradoja es que Thomson tenía un claro interés en enseñar a los jóvenes sefardíes el alfabeto latino y sus esquemas morfológicos derivacionales provenientes del latín, cuyo aprendizaje, según el misionero, les garantizaría una más rápida adquisición de otras lenguas europeas como el francés, el inglés o el italiano. Como el propio Thomson indicaría en su retraducción de La escalera en 1888: «estas nuevas palabras se uśan tođas en la lengua de España de hoy, y el niño que las entiende, entenderá también fácilmente las semejantes palabras en francéś, italiano y aun en ingléś» ${ }^{29}$. Por lo tanto, en dichas intenciones colonialistas vemos un

28 Vid. García Moreno, «Poemas castellanos», págs. 163 y 165.

29 Vid. Alexander Thomson, La escalera a la anveźadura (Constantinopla: A. H. Boyaciyan, 1888), pág. V. En la obra de Alexander Thomson, La escalera, se ejemplifica esta creencia en diversas ocasiones. Por ejemplo, el misionero destaca cómo se asemejan las palabras papel, papier y paper en español, francés e inglés respectivamente (pág. 279). De la misma manera, el traductor introduce neologismos en judeoespañol como son plató, fierro blanco o preris, provenientes del inglés plateau, white iron o prairies respectivamente. En este sentido, parece aún más interesante la introducción del vocablo mamal, una nueva forma en judeoespañol seguramente inventada por Thomson, una traducción directa del inglés mammal (mamífero). En la misma línea, el misionero incluye palabras inglesas en letras latinas, lo que contrasta con el texto aljamiado, como vacuum, o nombres propios como Shaftesbury (1801-1885), Sir John Herschel (17921871), Robert Stevenson (1772-1850), Dr. Joseph Black (1728-1799), Dr. McCulloch (?-?), el libro del científico Alexander Humboldt (1769-1859), Kosmos, así como términos científicos como farhenheit, Reaumur, Vernier, o ubicaciones como Saintes, Sevres en Francia, Saffi en Marruecos o Arbroath y Bell Rock en Escocia. 
cierto interés por introducir palabras del español moderno desconocidas en la Constantinopla sefardí de la época ${ }^{30}$. Algunos ejemplos significativos en esta línea son las codornices, emulando a Christie, cuando previamente había utilizado cuadernices; el adjetivo gorda, como también hace el otro misionero escocés, ignorando la metátesis característica en judeoespañol en godra, que sustituye al adjetivo magra ET1854. También se producirán casos aún más particulares como el del sustantivo calabaźa en la primera traducción, conocido en judeoespañol, que es sustituido por un término totalmente desconocido como calabacera en ET1886. Una vez más, no es de extrañar que esta palabra no tan prototípica en judeoespañol sí se lea en la historia de Jonás que traduce James Christie.

Cabe mencionar una de las principales sustituciones léxicas en la retraducción de Thomson, a saber, la de los nombres utilizados para referirse a Dios. El traductor muestra una predilección en ET1886 por la forma $H^{\prime}$, aunque este también aparecía con gran asiduidad en ET1854. En esta línea, hemos encontrado 181 casos donde el misionero ha empleado $H^{\prime}$ ' en vez de cualquier otro nombre en ET1886. Thomson cambia el título de Señor a $H^{\prime 31}$ hasta en 118 ocasiones y de Dio a $H^{\prime 32}$ hasta en 42 ocasiones. Estas sustituciones léxicas que venimos comentando podrían reflejar una elección basada en la traducción del Antiguo Testamento de su colega escocés. Sin embargo, Thomson también es propenso a incluir nombres menos comunes para la comunidad sefardí, como bien son el nombre יהוה / Yehová o las asociaciones que hace de Dios con ישוע המשיח Y Yešúa haMašíah, que claramente desafían los usos propios de los judíos de Constantinopla.

Finalmente, otros casos de sustituciones léxicas que deben tenerse en cuenta tienen que ver con extranjerismos como hebraísmos y turquismos. En cuanto a los primeros, siguen destacando los títulos de libros y otros nombres propios con origen hebreo, que siguen apareciendo en la retraducción con étimos hebreos. Este es el caso de Arba'á ve 'esrim (hb. (ארבעה ועשרים), Ba'al (hb. בעל) Ya'acob (hb. יעקב) entre muchos otros. De la misma manera, el misionero a veces emplea en su retraducción

30 Vid. García Moreno, «Poemas castellanos», págs. 160 y 200.

31 De las cuales 106 correspondían a the Lord, 10 veces a God, 1 vez a Lord of hosts y 1 vez a Moses en el original inglés compuesto por Barth.

32 De las cuales, 32 correspondían a God y 10 a the Lord en el original inglés. 
morfemas derivativos hebreos de número plural, tanto para el masculino

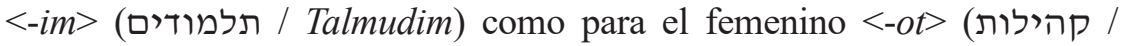
quehilot). Podemos también citar casos híbridos morfológicos a caballo entre español y hebreo, como con el vocablo araḅes (ערביס), diferente del español árabes y del hebreo ערבית / 'arabit. Cabe mencionar dos casos particulares relacionados a hebraísmos. Por un lado, vemos que el misionero tiende a sustituir el hebraísmo kohén / כהן por su traducción al español sacerdote en ET1886, lo cual parece ir en contra del proceso de sefardización del texto, pues la primera forma es más común que la segunda en el judeoespañol castizo decimonónico (aunque una vez más parece seguir el ejemplo de Christie en su traducción). Otro ejemplo que suscita interés es una excepción a los nombres propios de origen hebreo. Thomson utiliza Moisés 33 / מוייסיס, y no Mošé / משה, en una ocasión en La escalera para referirse a una persona con dicho nombre diferente del personaje bíblico. Ahora, en referencia a los turquismos, estos aparecen principalmente en La escalera y no en ET1886, los cuales el misionero adapta gráficamente en base a su pronunciación en turco ${ }^{34}$.

\section{Conclusiones}

Hemos procedido a dividir la producción de Thomson en dos períodos traductológicos principales, a saber, la década de 1850, momento cuando se tradujo la primera edición del Ele Toledot Bené Yisrael (Constantinopla, 1854), y la década de 1880, momento en el que se publicó la última retraducción de dicha obra (Constantinopla, 1886). Los cambios producidos entre ambas obras, publicadas con un lapso de 32 años, aunque significativos, no implican una mejora sustancial de la competencia en judeoespañol o en la traducción a este idioma en el momento de la retraducción. Es cierto que se perciben una ligeras mejoras en el último período. Por ejemplo, si el misionero se basaba en la grafía del español moderno pe-

\footnotetext{
33 Concretamente, Moisés Montefiore (1785-1885).

${ }^{34}$ Entre estos podemos citar baicúš (tc. baikuş 'búho'), carabatac (tc. karabatak 'cormorán', pero en verdad refiriéndose a 'somormujo'), chiźmes (tc. sg. çizme 'bota'), chorapes (tc. sing. çorap 'medias'), dovén (tc. döven 'mayal'), mahmuź (tc. mahmuz 'espuela'), mavi (tc. mavi 'azúl'), parmaclilc (tc. parmaklık 'valla') y quiemán (tc. keman 'violín').
} 
ninsular a la hora de escribir ciertas palabras en judeoespañol, en el último período pone más énfasis en la conexión fonema-grafema de la lengua meta para escribir esas mismas palabras en el idioma sefardí. Sin embargo, al igual que en la década de 1850, la etapa final aún sigue caracterizándose por interferencias del inglés y confusiones entre lo perteneciente al español normativo decimonónico y al judeoespañol castizo. En el plano léxico, el misionero tiende a sustituir vocablos por términos más sefardizados, aunque no renuncia a incluir neologismos provenientes del español moderno o el inglés, a veces incluso añadiendo nuevas acepciones protestantes a palabras ya existentes en la lengua meta, fomentando con ello un intento de aculturación de la comunidad sefardí.

En definitiva, podemos concluir cinco puntos principalmente.

Primero, la lengua que encontramos en la retraducción aún no puede ser considerada plenamente judeoespañol decimonónico. Es más, en algunos casos se puede incluso considerar que exista un empeoramiento de ciertas construcciones y usos mejor traducidos en la década de 1850 que en la retraducción de la década de 1880.

Segundo, en relación a este fenómeno, algunos acontecimientos en la vida del misionero pudieron afectar a todo el proceso que venimos comentando en este estudio. Hablamos concretamente del abandono de Thomson del puesto de maestro en Hasköy, lo que conllevó a una pérdida de contacto con el idioma meta para dedicarse a la traducción bíblica de otras lenguas como el albanés.

Tercero, también en relación a nuestra primera conclusión, hemos demostrado la similitud en determinadas características lingüísticas, aunque no siempre y de manera sistemática, entre la traducción de la Biblia al judeoespañol de 1873 (Constantinopla) del otro misionero escocés, James Christie, y las retraducción de Thomson. Y es que el segundo podría estar tomando como punto de referencia lingüístico al primero para retraducir ET1886 o La escalera (Constantinopla, 1888). Dicho de otra manera, el hecho de que ET1886 sea un compendio de historias bíblicas, junto al hecho de que la traducción bíblica de Christie apareciera una década antes de la publicación de estas, nos llevan a pensar que Thomson utilizó dicha traducción bíblica como modelo para realizar muchos de los cambios lingüísticos que encontramos en su última retraducción de Dr. Barth's Bible Stories. 
Cuarto, las coincidencias textuales entre ET1886 y la traducción de Christie en 1873 llaman la atención pero no son sistemáticas, por lo que no podemos hablar de un caso de transferencia textual completo, ya que hemos visto en no pocas ocasiones como Thomson decide ignorar el texto de Christie, aunque ello no acabe beneficiando a la calidad de su retraducción.

Quinto, no creemos que la calidad o precisión de las traducciones y retraducciones de Thomson deba ser fehacientemente emulada en otros traductores no nativos del judeoespañol como lengua objetivo, y el contexto personal del traductor aquí no debiera extrapolarse a ningún otro autor contemporáneo. Más bien, la lengua del misionero es un idiolecto muy especial, así como su competencia traductológica. Por ejemplo, dudamos que todos los hablantes nativos de inglés sean conocedores de la gramática y léxico hebreo como Thomson, o que tengan dichos fines proselitistas a la hora de aprender este idioma.

Futuros nuevos estudios sobre la producción del misionero podrían ser de gran utilidad a la hora de determinar la evolución de las traducciones al judeoespañol en el caso de Thomson. Un factor fundamental en esta línea sería la transcripción de la primera retraducción de Ele Toledot Bené Yisrael (1868), pues supondría una fase intermedia entre dos períodos de producción tan distantes en el tiempo. Nuevas investigaciones también deberían explorar la influencia de las casas editoriales que publicaron la primera traducción de la obra y su última retraducción, pues son diferentes y podrían aportar otro punto de vista para saber el porqué de las diferencias lingüísticas aquí comentadas entre uno y otro período.

En cualquier caso, consideramos que la lengua de Thomson es el resultado de dos fuerzas antagónicas que definen su estilo y usos lingüísticos. Por un lado, hay un intento de convergencia lingüístico-social a la comunidad sefardí en la que se quiere integrar. Por otro lado, hay una clara divergencia, pues el fin último pedagógico del misionero no era la enseñanza del judeoespañol aljamiado sino la escritura en letras latinas del propio idioma y el aprendizaje del castellano moderno peninsular. Estas tendencias opuestas bien podrían explicar el porqué de la vacilante evolución de la lengua apreciada en las traducciones del misionero.

Recibido: $16 / 10 / 2019$

Aceptado: 17/03/2020 